\title{
Kip of ei; De juiste focus in het vraagstuk van kwaliteit van de accountantscontrole?
}

Barbara Majoor

De vraag hoe de kwaliteit van accountantscontrole kan worden verbeterd houdt vele partijen al geruime tijd bezig. Deze aandacht heeft recentelijk weer een stimulans gehad met de publicatie van het rapport van de AFM (2017) 'Kwaliteit onderzocht'. De conclusie van de AFM was namelijk dat het verandertraject bij de onderzochte OOB-accountantsorganisaties te langzaam gaat en dat de kwaliteit van de onderzochte wettelijke controle bij de Big 4-accountantsorganisaties niet op orde is (AFM, 2017, p. 4). Genoeg reden dus om deze vraag opnieuw hoog op de agenda te zetten, wat bij mij de vraag oproept wat de focus is van de sector.

\section{Onduidelijkheid over het begrip controlekwaliteit?}

Er is veel aandacht voor het vraagstuk van definiëring van controlekwaliteit. In deze discussie gaat het om de constatering dat controlekwaliteit een complex begrip is. Een begrip waarover nog geen eenduidige visie bestaat die door alle stakeholders wordt erkend en waarbij de vraag opkomt of het wenselijk is om een generieke definitie te formuleren die voor alle stakeholders van toepassing is. Deze constateringen die door diverse partijen en wetenschappers zijn gedaan (Knechel et al., 2013) prikkelt daarmee de natuurlijke reactie om duidelijkheid te willen krijgen over wat controlekwaliteit is voor de verschillende stakeholders. De wetenschap en regelgevende partijen hebben dit vraagstuk opgepakt. Bijvoorbeeld de NBA heeft een green paper (2017) gepubliceerd met het doel om "te komen tot een meer inhoudelijke en eenduidige invulling van het begrip audit kwaliteit" (NBA, 2017a, p. 3). De toepassing van een multi-stakeholder perspectief juich ik van harte toe. Voor wetenschappers kan dit behulpzaam zijn in de operationalisatie van het begrip om daarmee concrete uitspraken te doen over de controlekwaliteit voor de verschillende groepen stakeholders. Voor de praktijk is het relevant omdat dan de verwachtingskloof tussen wat accountants aan zekerheid verschaffen en wat de maatschappij verwacht (de zogenoemde 'reasonableness gap') (NBA, 2017a, p. 6) kan worden verkleind. Als exact duidelijk is wat de wensen zijn van de diverse stakeholders, kan het product (de accountants- controle) daar naadloos op worden afgestemd. Daarmee zou in theorie een belangrijk deel van de verwachtingskloof (die van de niet begrepen maatschappelijke verwachtingen) opgelost zijn.

Een kanttekening die ik daarbij plaats is dat door deze discussie de aandacht wordt afgeleid van de huidige 'performance gap' (dat de accountants niet voldoen aan de gerechtvaardigde verwachtingen van de maatschappij). Er dreigt een kip-of-ei-discussie te ontstaan, met het risico dat daardoor de verbeteringen die nodig zijn in het product; de implementatie van de kwaliteitsslag wordt vertraagd. Dit roept de vraag op wat er drie jaar na de publicatie van het rapport "In het publiek belang" (NBA, 2014) door de sector is gerealiseerd?

\section{Onderscheid tussen audit quality en een quality audit}

Het onderscheid tussen beide vraagstukken heeft de IAASB (2016) treffend verwoord in het verschil tussen 'audit quality' en een 'quality audit'. Audit quality staat ervoor dat de geleverde kwaliteit aansluit op de behoefte van de stakeholders. Een quality audit wordt bereikt als er adequate controlewerkzaamheden worden uitgevoerd, adequaat gerapporteerd, onder andere via de controleverklaring en tijdige en volledige communicatie met relevante stakeholders plaatsvindt op een objectieve en integere wijze. Kortom als een controle wordt uitgevoerd in overeenstemming met de controlestandaarden.

\section{Voldoende aandacht voor een quality audit of...?}

Om een antwoord te vinden op wat er drie jaar na de publicatie van het rapport "In het publiek belang" (NBA, 2014) is gerealiseerd ga ik in het vervolg van deze column in op enkele aspecten van een quality audit. Hierbij hanteer ik een model dat is ontleend aan het Audit Quality Framework zoals dat door de FRC (2008) is opgesteld. Dit model benoemt de zogenoemde 'drivers' voor een quality audit. Cultuur van een accountantsorganisatie en professional scepticism worden in dit model onder andere als driver benoemd voor een quality audit. Deze twee drivers komen voor een 
groot deel overeen met de belangrijkste oorzaak die in het rapport "In het publiek belang" (NBA, 2014) is benoemd voor de incidenten die het beroep hebben beschadigd en daarmee uitgangspunt zijn geweest voor de verbetermaatregelen. "Als er een cultuur is waarin kwaliteit bovenaan staat, waarin tegenspraak en een professioneel-kritische instelling hogelijk worden gewaardeerd, dan zal dat het risico op dergelijke incidenten sterk reduceren. Als die cultuur er niet is, dan is dat een voedingsbodem voor incidenten waarbij mensen verkeerde keuzes maken" (NBA, 2014, p. 8). Om aan de maatschappelijke verwachtingen te voldoen is een cultuurverandering nodig die kwaliteit als hoogste doel stelt en ruimte geeft aan een professioneel-kritische instelling. De concurrentieslag zou dan moeten gaan over wie de beste kwaliteit levert en niet wie het goedkoopst is. Is deze omslag in 2017, drie jaar na de publicatie van het rapport "In het publiek belang" gerealiseerd?

Recente publicaties (AFM, 2017 en NBA, 2017b) geven aan dat er nog veel werk aan de winkel is, waar het gaat om de realisatie van een kwaliteitsgerichte cultuur. Analyse van beide rapporten leert dat bij accountantsorganisaties de realisatie van een kwaliteitsgerichte cultuur achterblijft. Dat is een stevige boodschap. Het is tijd om uit te zoeken waar de schoen wringt. Vragen die daarbij kunnen helpen zijn bijvoorbeeld of de leiding als boegbeeld van de verandering 100\% gecommitteerd is aan de focus op kwaliteit en het in alle situaties prioriteit geven aan kwaliteit in het publiek belang. Mixed signalen, bijvoorbeeld door het nastreven van conflicterende strategische doelstellingen is een recept voor het stuklopen van de verandering. Als drijvende kracht van gedrag en cultuur is een dominant patroon noodzakelijk binnen een complex netwerk van formele, informele en impliciete gebruiken, regels en beleidsbeslissingen in de gehele organisatie. Een tweede drijvende kracht die in het FRC-model wordt benoemd voor een quality audit is de vaardigheid van accountants om professioneel-kritisch te zijn. Er is zorg bij de standardsetters of accountants in voldoende mate hun professioneel-kritische houding laten zien en toepassen in de controlewerkzaamheden. Een gezamenlijke werkgroep van de IAASB, IESBA en IAESB (2017) benoemt deze zorg als volgt: "The importance of professional skepticism to the public interest is underscored by the increasing complexity of business and financial reporting, including greater use of estimates and management judgments, changes in business models brought about by technological developments, and the fundamental reliance the public places on reliable financial reporting" (IAASB, IESBA \& IAESB, 2017, p. 3). Dit roept enerzijds vragen op of de toepassing van dit concept voldoende is geborgd in de controlestandaarden. Kan de accountant de toepassing duidelijker laten zien in zijn verklaring en docu- mentatie van werkzaamheden? Anderzijds juist vragen of de controlestandaarden voldoende ruimte laten voor de toepassing van een kritische mindset of dat de standaarden de toepassing juist beperken door een te grote mate van compliance. Wat is er in deze discussies, drie jaar na de publicatie van het rapport "In het publiek belang” (NBA, 2014), gerealiseerd? De diepgaande inhoudelijke discussie over dit vraagstuk is in de afgelopen jaren in Nederland te weinig gevoerd en niet veel verder gekomen dan een algeheel gevoelen dat een checklist-benadering niet de oplossing is, maar wat dan wel?

De IAASB heeft onderkend dat een quality audit en professional skepticism kernvraagstukken zijn als het gaat om controles uit te voeren in het publiek belang en heeft daar in 2016 een consultatie paper (IAASB, 2016) over geschreven, waarin zij input vraagt op haar visie op het realiseren van een quality audit. De genoemde werkgroep (IAASB, IESBA \& IAESB, 2017) heeft recent een paper geschreven die een aantal observaties bespreekt over het belang van professional skepticism en de initiatieven die de drie betrokken standardsetters nemen op dat terrein.

Deze initiatieven zijn goed om meer inzicht in een complex vraagstuk te krijgen en om het belang van een quality audit te onderstrepen. Tegelijkertijd geeft het een signaal of er voldoende daadkracht, actie en urgentie wordt gevoeld bij accountants. De tijd verloopt en concrete antwoorden vanuit de sector en de regelgevende instanties blijven uit. Het ontbreken van antwoorden wakkert (on)bewust de sluimerende discussie aan over radicalere oplossingen dan de hiervoor besproken richtingen. Daarmee komt de tijdshorizon van andere oplossingen dichterbij. Andere oplossingen die zich mogelijk gaan richten op fundamentele verandering in de onderliggende uitgangspunten van het huidige verdienmodel van accountants. Ik ben ervan overtuigd dat met enige creativiteit er een scala aan alternatieven te bedenken is. De vraag is wie daarvoor het startsein geeft of dat de tijd hierin haar werk doet.

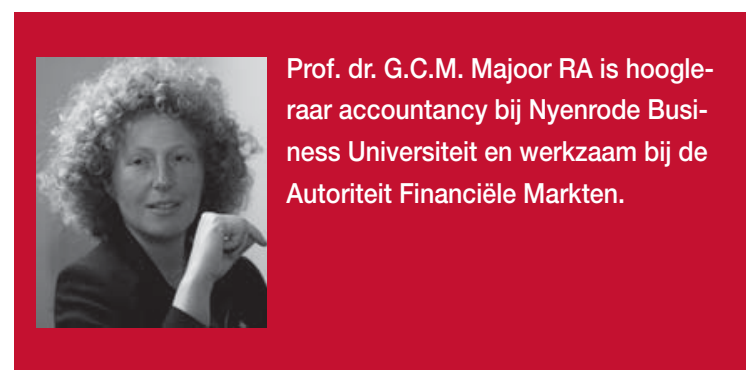




\section{Literatuur}

- AFM, Autoriteit Financiële Markten (2017). Kwaliteit OOB-accountantsorganisaties onderzocht: Uitkomsten van onderzoeken naar de implementatie en borging van verandertrajecten bij de OOB-accountantsorganisaties en de kwalliteit van wettelijke controles bij de Big 4-accountantsorganisaties. Geraadpleegd op https://www.afm.nl/ /profmedia/files/rapporten/2017/0ob/deel-1.ashx

- FRC, Financial Reporting Council (2008). The Audit Quality Framework. London: FRC. Geraadpleegd op https://frc.org.uk/Our-Work/ Publications/FRC-Board/The-Audit-QualityFramework-(1)-File.pdf.

- IAASB, International Auditing and Assurance Standards Board (2016). Enhancing Audit Quality In The Public Interest. Geraadpleegd op https://www.ifac.org/publications-resources/invitation-comment-enhancing-audit-quality-public-interest.

- IAASB, International Auditing and Assurance Standards Board, EESBA, International Ethics
Standards Board for Accountants, IAESB, the International Accounting Education Standards Board (2017). Toward enhanced professional scepticism: Observations of the IAASB-IAESBIESBA Professional scepticism working group. Geraadpleegd op http://www.ifac.org/system/ files/publications/files/Toward-Enhanced-Professional-Skepticism-IAASB-AEESB-IESBA.pdf.

- IFIAR, The International Forum of Independent Audit Regulators (2017). Report on 2016 survey of inspection findings. Geraadpleegd op https://wwwififiar.org/download/2016-surveyof-inspection-findings/?wpdmdl=2055\&ind= 5LfgFm5HCCI04M105JpKn-YiVRJJCn5OWrDRDumt3Se6PFBB9OFLkM7SwUUmWwhnHVGfy_DmELL8C_Or_h_VW.

- Knechel, W. Krishnan, G., Pevzner, M., Shefchik, L., \& Velury, U. (2013). Audit quality: Insights from the academic literature. Auditing: A Journal of Practice \& Theory, 32(Supplement 1): 385-421.

- NBA, Koninklijke Nederlandse Beroepsorgani- satie van Accountants, Werkgroep Toekomst Accountantsberoep (2014). In het publiek belang: Maatregelen ter verbetering van de kwaliteit en onafhankelijkheid van de accountantscontrole. Geraadpleegd op https://www. accountant.n//globalassets/accountant.nl/ toekomst-accountantsberoep/ in_het_publiek_belang_rapport_25sep2014.pdf.

- NBA, Koninklijke Nederlandse Beroepsorganisatie van Accountants (2017a). Green paper: De definitie van audit kwaliteit. Geraadpleegd op https://www.accountant.n//globalassets/ accountant.n//toekomst-accountantsberoep/ green_paper_audit_quality.pdf.

- NBA, Koninklijke Nederlandse Beroepsorganisatie van Accountants (2017b). Accountancy Cultururmeter: Nulmeting. Geraadpleegd op https://www.nba.n//globalassets/blokken-interne-links-zonder-kopjes/nieuws/nba-sracultuurmeter_nulmeting_juni_2017.pdf. 